\title{
PENENTUAN KEPUTUSAN INVESTASI SAHAM MENGGUNAKAN CAPITAL ASSET PRICING MODEL (CAPM) DENGAN PENAKSIR PARAMETER STOKASTIK
}

\author{
Icha Winda Dian Safira ${ }^{1 \S}$, Komang Dharmawan², Desak Putu Eka Nilakusmawati ${ }^{3}$
}

\author{
${ }^{1}$ Program Studi Matematika, FMIPA, Universitas Udayana [Email: ichawindadiansafira@gmail.com] \\ ${ }^{2}$ Program Studi Matematika, FMIPA, Universitas Udayana [Email: k.dharmawan @unud.ac,id] \\ ${ }^{3}$ Program Studi Matematika, FMIPA - Universitas Udayana [Email: nilakusmawati@unud.ac.id] \\ ${ }^{\S}$ Corresponding Author
}

\begin{abstract}
CAPM is a method of determining efficient or inefficient stocks based on the differences between individual returns and expected returns based on the CAPM's positive value for efficient and negative value for inefficient stocks. The move to share prices in the process can influence investors's decisions in investing funds, so that it can be formulated in stochastic differential equations that form the Geometric Brownian Motion model (GBM). The purpose of the study is to determine return value using the CAPM based on share estimates and historical stock prices. The study uses secondary data that data a monthly closing of stock prices from December 2017 to December 2020. The GBG model's estimated stock price is used to determine the expected value return using the CAPM. In this case, it is called CAPM-Stochastic. Then the results of the CAPM-Stochastic was compared to the results of the $C A P M$-Historical to define efficient stocks and inefficient stocks. The results of research using CAPMStochastic obtained that HMSP, ICBP, KLBF, and WOOD shares are efficient stock while UNVR shares are inefficient. The results of CAPM-Historical obtained that HMSP, ICBP, KLBF, and UNVR shares are inefficient stocks and WOOD is an efficient stocks.
\end{abstract}

Keywords: Geometric Brownian Motion, CAPM-Stochastic, Efficient Stock

\section{PENDAHULUAN}

Dunia investasi di Indonesia akhir-akhir ini mulai banyak dilirik oleh masyarakat dari berbagai kalangan, tidak hanya dari kalangan investor tetapi juga banyak menarik perhatian kalangan masyarakat dan generasi muda zaman sekarang. Salah satu jenis instrumen keuangan yang paling banyak diperdagangkan di pasar modal adalah saham. Dalam kegiatan investasi, pergerakan harga saham ditandai oleh adanya indeks harga saham. Salah satu indeks harga saham di Indonesia adalah indeks Sektor Industri Barang Konsumsi.

Investasi saham pada pasar modal untuk memperoleh tingkat pengembalian (return). Dalam berinvestasi investor mengusahakan agar memperoleh tingkat pengembalian terbesar dengan risiko tertentu. Sehingga dalam berinvestasi saham pada pasar modal, investor diharapkan dapat menentukan keputusan investasi sesuai dengan profil risikonya untuk meminimalkan risiko yang akan diperoleh.
Oleh karena itu, diperlukan model keseimbangan untuk menentukan hubungan antara risiko dan tingkat pengembalian yang diharapkan untuk setiap aset dalam keadaan pasar yang seimbang. Model tersebut adalah capital asset pricing model (CAPM). CAPM dapat digunakan untuk menentukan sahamsaham efisien pada suatu sekuritas berdasarkan tingkat pengembalian yang diharapkan lebih kecil dari tingkat pengembalian saham individu (Tandelilin, 2017). Risiko dalam CAPM diukur oleh variabel yang disebut beta $(\beta)$.

Penelitian terdahulu yang menggunakan CAPM dalam menentukan saham efisien yaitu pada penelitian Liadi, dkk. (2020) dan Haidiati, dkk. (2016). Kedua penelitian tersebut menggunakan CAPM dengan perhitungan beta langsung menggunakan data harga saham historis. Ameliah dkk. (2017) membandingkan perhitungan risiko (beta) dengan CAPM dengan perhitungan beta diestimasi menggunakan GARCH dan EGARCH. 
Sedangkan penelitian ini akan menentukan CAPM berdasarkan data harga saham yang diestimasi terlebih dahulu.

Fluktuasi harga saham yang selalu berubah dapat memengaruhi keputusan investor dalam menginvestasikan dananya. Pergerakan harga saham tersebut mengikuti proses stokastik sehingga dapat dirumuskan dalam persamaan diferensial stokastik. Berdasarkan Yunita dkk. (2015), persamaan diferensial stokastik disajikan dalam model matematis untuk mengestimasi harga saham yang akan membentuk suatu model dinamakan Gerak Brown Geometri (GBG). Model GBG digunakan karena model ini sesuai untuk mengestimasi harga saham pada masa yang akan datang dalam investasi (Abidin dan Jaffar, 2014).

Pada penelitian ini perolehan harga saham yang telah diestimasi menggunakan GBG menjadi bahan kajian selanjutnya dalam menentukan CAPM. Kemudian, hasil yang diperoleh akan dibandingkan berdasarkan hasil perhitungan CAPM menggunakan GBG dan CAPM menggunakan data historis.

Husnan (2015), menentukan persamaan CAPM untuk menghitung tingkat pengembalian yang diharapkan dari suatu sekuritas adalah sebagai berikut:

$$
E\left(r_{i}\right)=r_{f}+\left(E\left(r_{M}\right)-r_{f}\right) \beta_{i}
$$

dengan $E\left(r_{i}\right)$ adalah tingkat pengembalian yang diharapkan dari saham ke-i, $r_{f}$ adalah tingkat pengembalian bebas risiko, $E\left(r_{M}\right)$ adalah tingkat pengembalian indeks pasar, dan $\beta_{i}$ adalah risiko dari saham ke-i. Berikut ini adalah cara untuk mengukur beta dari suatu saham:

$$
\beta_{i}=\frac{\left.\sum_{t=1}^{n}\left(r_{i}-\bar{r}_{i}\right) \cdot\left(r_{M}-\bar{r}_{M}\right)\right)}{\sum_{t=1}^{n}\left(r_{M}-\bar{r}_{M}\right)^{2}}
$$

Mengacu pada Dmouj (2006), model GBG dapat ditentukan sebagai berikut:

$$
d S_{t}=\mu S_{t} d t+\sigma S_{t} d W_{s}
$$

dengan $S_{t}$ adalah harga saham pada saat $t, \mu$ adalah ekspektasi return saham, $\sigma$ adalah standar deviasi dari return saham dan $W_{s}$ adalah Gerak Brown yang dimulai pada $W_{0}=0$.

Pada ruas kanan persamaan (3) adalah proses Gerak Brown yang merupakan unsur stokastik sehingga untuk menyelesaikan persamaan (3) digunakan penerapan dari Lemma Ito, fungsi $G=G(S, t)$ yaitu:

$$
\begin{aligned}
& d G=\left(\frac{\partial G}{\partial S_{t}} \mu S_{t}+\frac{\partial G}{\partial t}+\frac{1}{2} \frac{\partial^{2} G}{\partial S_{t}^{2}} \sigma^{2} S_{t}^{2}\right) d t+ \\
& \frac{\partial G}{\partial S_{t}} \sigma S_{t} d W_{s}
\end{aligned}
$$

Dari Lemma Ito, fungsi $G=G(S, t)$ pada persamaan (4) akan diperoleh:

$S_{t}=S_{t-1} \exp \left[\left(\mu-\frac{1}{2} \sigma^{2}\right) \Delta t+\sigma d W_{s}\right]$

Sehingga dapat dinyatakan bahwa harga saham pada masa depan mengikuti model GBG seperti pada persamaan (5).

\section{METODE PENELITIAN}

Data yang digunakan adalah data penutupan harga saham bulanan pada perusahaan di sektor industri barang konsumsi periode Desember 2017 hingga Desember 2020. Perusahaanperusahan yang akan diteliti berada di kelima subsektor tersebut, yaitu PT. Indofood CBP Sukses Makmur Tbk. (ICBP), PT. H.M. Sampoerna Tbk. (HMSP), PT. Kalbe Farma Tbk. (KLBF), PT. Unilever Indonesia Tbk. (UNVR), dan PT. Integra Indocabinet Tbk. (WOOD).

Langkah-langkah yang digunakan dalam penelitian ini adalah:

1. Mengumpulkan data harga saham bulanan pada masing-masing saham periode Desember 2017 hingga Desember 2020.

2. Menghitung tingkat pengembalian (return) dari masing-masing saham.

3. Menentukan CAPM menggunakan GBG pada masing-masing saham.

a. Melakukan estimasi harga saham terhadap masing-masing saham menggunakan model GBG.

b. Menghitung tingkat pengembalian (return) pada masing-masing saham berdasarkan perolehan data harga saham estimasi menggunakan model GBG.

c. Menghitung tingkat pengembalian pasar.

d. Menghitung beta masing-masing saham dengan CAPM setelah memperoleh hasil return berdasarkan perolehan harga saham estimasi.

e. Menentukan tingkat pengembalian yang diharapkan dari masing-masing saham berdasarkan CAPM menggunakan GBG.

4. Menentukan CAPM pada masing-masing saham menggunakan data historis.

5. Membandingkan hasil perhitungan tingkat pengembalian yang diharapkan dari CAPM menggunakan GBG dan CAPM menggunakan data historis. 


\section{HASIL DAN PEMBAHASAN}

\subsection{Desk ripsi Data}

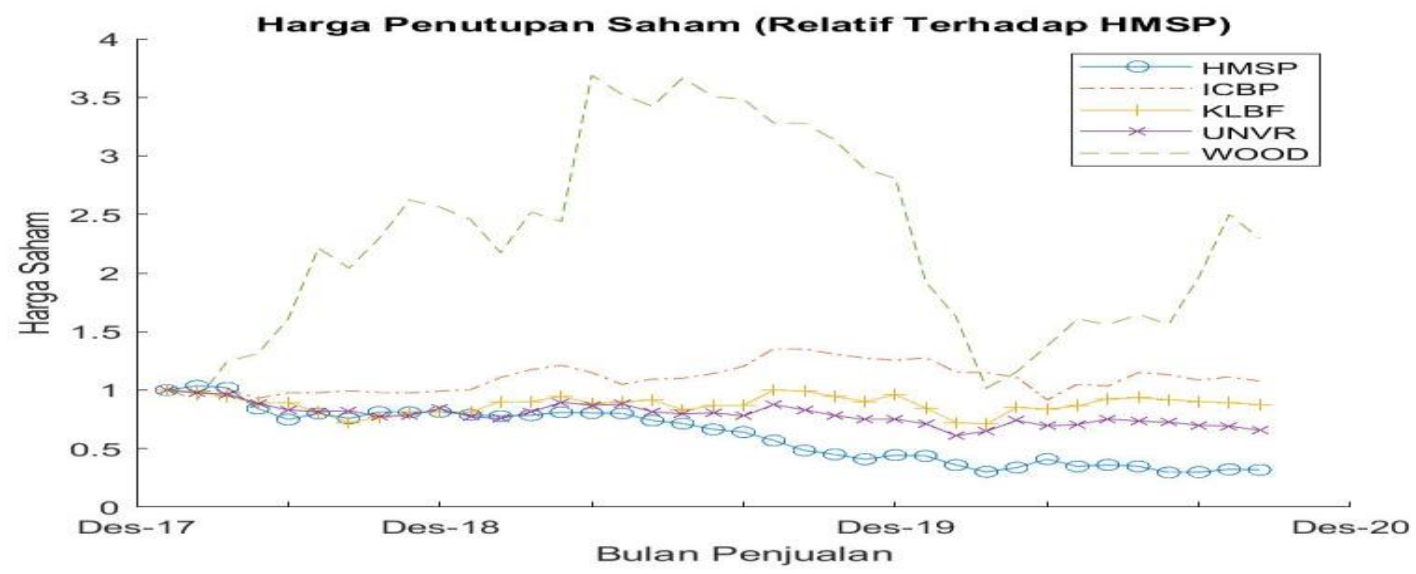

Gambar 1. Plot Harga Saham HMSP, ICBP, KLBF, UNVR, dan WOOD.

Berdasarkan Gambar 1 harga saham HMSP dan UNVR mengalami penurunan yang signifikan hingga akhir periode. Kemudian harga saham ICBP dan KLBF cenderung datar dengan fluktuatif. Sedangkan harga saham WOOD mengalami fluktuasi yang signifikan pada seluruh periode.

\subsection{Menentukan Nilai Return Pada Masing- masing Saham}

Perhitungan nilai return pada masingmasing saham, sebagai contoh pada saham
ICBP harga saham pada bulan Januari 2018 adalah Rp 8900 dan bulan Desember 2017 adalah $\mathrm{Rp} 8725$ maka tingkat pengembalian (return) saham ICBP adalah:

$$
\begin{aligned}
& r_{1}=\ln \left(\frac{8900}{8725}\right) \\
& r_{1}=-0,01986
\end{aligned}
$$

Nilai $r_{1}=-0,01986$ menunjukkan bahwa return saham mengalami penurunan sebesar $1,986 \%$ dibandingkan dengan sebelumnya. Nilai return dapat disajikan pada Gambar 2.

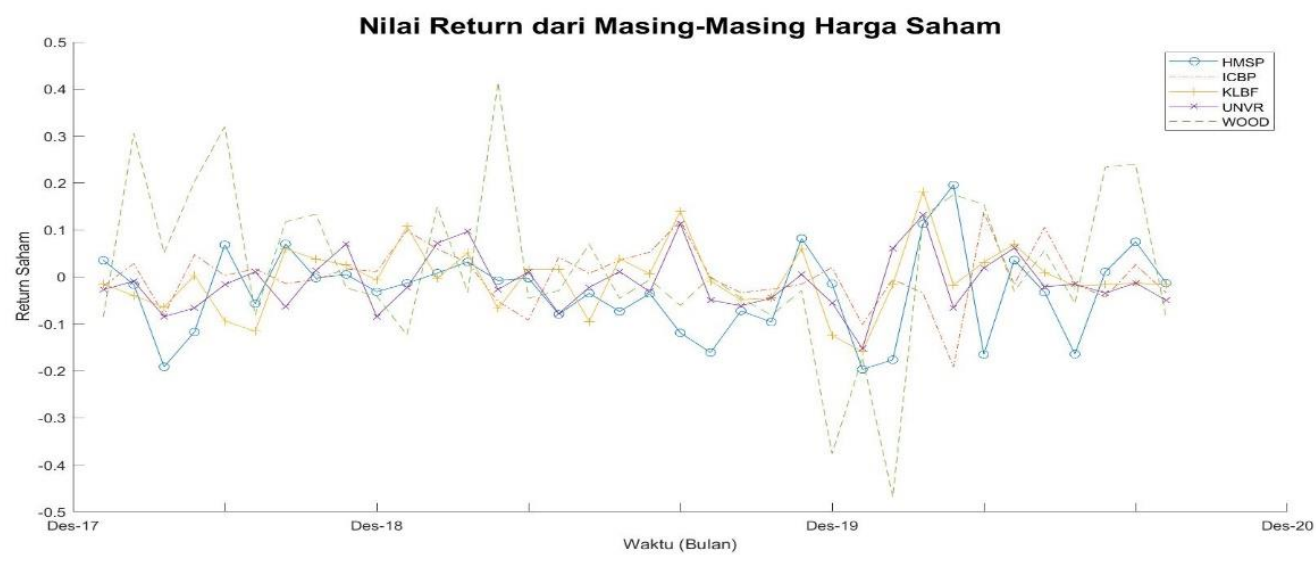

Gambar 2. Nilai Return Saham HMSP, ICBP, KLBF, UNVR, dan WOOD

Pada Gambar 2 dapat dilihat bahwa return saham HMSP, ICBP, KLBF, dan UNVR cenderung mengalami fluktuasi yang naik turun hingga akhir periode. Return saham WOOD pada Bulan Januari hingga April 2020 mengalami fluktuasi naik turun yang cukup signifikan.

\subsection{Model Gerak Brown Geometri}

Dalam proses estimasi harga saham, data yang digunakan adalah data harga penutupan saham bulanan dari Bulan Desember 2017 hingga Desember 2020 dalam menentukan parameter untuk membangun model simulasi harga saham. 


\subsubsection{Menentukan Parameter dalam Model Gerak Brown Geometri}

Dalam bentuk model estimasi harga saham terdapat dua parameter yaitu parameter $\mu$ dan parameter $\sigma$. Hasil perhitungan parameter dalam membangun model GBG disampaikan pada Tabel 1.

Tabel 1. Estimasi Parameter dalam Model GBG

\begin{tabular}{|c|c|c|}
\hline Saham & $\mu$ & $\sigma$ \\
\hline HMSP & $-0,0318$ & 0,0910 \\
\hline ICBP & 0,0020 & 0,0635 \\
\hline KLBF & $-0,0037$ & 0,0702 \\
\hline UNVR & $-0,0117$ & 0,0608 \\
\hline WOOD & 0,0231 & 0,1764 \\
\hline
\end{tabular}

\subsubsection{Estimasi Harga Saham Menggunakan Model Gerak Brown Geometri}

Setelah diperoleh nilai parameter pada uraian sebelumnya, kemudian langkah selanjutnya adalah menyubstitusikan nilai parameter tersebut ke dalam model GBG dengan dengan $\Delta t=1 / 242$ merupakan periode untuk mengestimasi harga selama 242 hari dalam satu tahun dan harga saham awal menggunakan data harga Bulan Desember 2020 yang disajikan pada Tabel 2 .

Harga yang diestimasi dengan periode 242 hari selama satu tahun pada setiap saham menghasilkan 242 harga yang diubah ke bulanan dengan mengambil harga pada akhir bulan. Sehingga terdapat 12 harga saham bulanan pada setiap saham.

Tabel 2. Model Estimasi Harga Saham dengan Gerak Brown Geometri

\begin{tabular}{|c|c|c|}
\hline No. & Saham & Model Estimasi Harga Saham dengan Gerak Brown Geometri \\
\hline 1. & HMSP & $S_{t}=(1505) \exp \left[\left(-0,0318-\frac{1}{2}(0,0910)^{2}\right)\left(\frac{1}{242}\right)+(0,0910) \varepsilon \sqrt{\frac{1}{242}}\right]$ \\
\hline 2. & ICBP & $S_{t}=(9575) \exp \left[\left(0,0020-\frac{1}{2}(0,0635)^{2}\right)\left(\frac{1}{242}\right)+(0,0635) \varepsilon \sqrt{\frac{1}{242}}\right]$ \\
\hline 3. & KLBF & $S_{t}=(1480) \exp \left[\left(-0,0037-\frac{1}{2}(0,0702)^{2}\right)\left(\frac{1}{242}\right)+(0,0702) \varepsilon \sqrt{\frac{1}{242}}\right]$ \\
\hline 4. & UNVR & $S_{t}=(7350) \exp \left[\left(-0,0117-\frac{1}{2}(0,0608)^{2}\right)\left(\frac{1}{242}\right)+(0,0608) \varepsilon \sqrt{\frac{1}{242}}\right]$ \\
\hline 5. & WOOD & $S_{t}=(560) \exp \left[\left(0,0231-\frac{1}{2}(0,1764)^{2}\right)\left(\frac{1}{242}\right)+(0,1764) \varepsilon \sqrt{\frac{1}{242}}\right]$ \\
\hline
\end{tabular}

\subsection{Menentukan Capital Asset Pricing Model (CAPM)}

Setelah memperoleh data harga saham bulanan pada masing-masing saham yaitu data harga saham estimasi dan data harga saham historis selanjutnya data harga saham-saham tersebut digunakan untuk menentukan CAPMStokastik dan CAPM-Historis.

\subsubsection{Return Berdasarkan Harga Saham Estimasi}

Hasil perhitungan return berdasarkan harga saham estimasi diperoleh bahwa nilai rata-rata return saham HMSP adalah -0,00297, ICBP adalah -0,00007, KLBF adalah -0,00057, UNVR adalah $-0,00091$, dan WOOD adalah 0,00203 . Dari kelima saham tersebut nilai ratarata return tertinggi dimiliki oleh saham
WOOD dan nilai rata-rata return terendah dimiliki oleh saham HMSP.

\subsubsection{Return Berdasarkan Harga Saham Historis}

Hasil perhitungan return berdasarkan harga saham historis diperoleh bahwa nilai rata-rata return saham HMSP adalah -0,03181, ICBP adalah 0,00203, KLBF adalah -0,00369, UNVR adalah -0,01165, dan WOOD adalah 0,02308 . Dari kelima saham tersebut nilai ratarata return tertinggi dimiliki oleh saham WOOD dan nilai rata-rata return terendah dimiliki oleh saham HMSP.

\subsubsection{Nilai Return Pasar Historis dan Pasar Estimasi}

Berdasarkan perhitungan diperoleh nilai rata-rata tingkat pengembalian pasar historis 
$\left(E\left(R_{M}\right)\right)$ sebesar $-0,00047$ dan nilai rata-rata tingkat pengembalian pasar estimasi $\left(E\left(R_{M}\right)\right)$ sebesar $-0,00022$.

\subsubsection{Beta $\left(\beta_{i}\right)$ CAPM Masing-Masing Saham}

Beta merupakan suatu pengukur volatilitas return suatu sekuritas terhadap return pasar. Hasil perhitungan nilai beta CAPM-Stokastik dan beta CAPM-Historis dapat dilihat pada Tabel 3. Salah satu contoh proses perhitungan nilai Beta $\left(\beta_{i}\right)$ CAPM-Stokastik pada saham HMSP adalah sebagai berikut:

$$
\begin{gathered}
\beta_{i}=\frac{\left.\sum_{t=1}^{n}\left(r_{i}-\bar{r}_{i}\right) \cdot\left(r_{M}-\bar{r}_{M}\right)\right)}{\sum_{t=1}^{n}\left(r_{M}-\bar{r}_{M}\right)^{2}} \\
\beta_{i}=\frac{((0,00017-(-0,00297) \cdot(0,00148-(-0,00022))+\cdots+}{((-0,00663-(-0,00297) \cdot(-0,00222-(-0,00022))} \\
\beta_{i}=\frac{(0,00148-(-0,00022))^{2}+\cdots+}{(-0,00222-(-0,00022))^{2}} \\
\beta_{i}=\frac{0,00003108) \cdot(0,0017)+\cdots+((-0,00366) \cdot(-0,00199))}{0,00001635} \\
\beta_{i}=1,90030
\end{gathered}
$$

Tabel 3. Hasil Perhitungan Beta CAPMStokastik dan CAPM-Historis Pada Masingmasing Saham

\begin{tabular}{|c|c|c|}
\hline Saham & $\begin{array}{c}\text { Beta CAPM- } \\
\text { Stokastik }\end{array}$ & $\begin{array}{c}\text { Beta CAPM- } \\
\text { Historis }\end{array}$ \\
\hline HMSP & 1,90030 & 1,18075 \\
\hline ICBP & 1,29882 & 0,20786 \\
\hline KLBF & 1,44293 & 0,67198 \\
\hline UNVR & 0,38044 & 0,27375 \\
\hline WOOD & 1,05731 & 1,67418 \\
\hline
\end{tabular}

Pada Tabel 3 perhitungan beta berdasarkan CAPM-Stokastik pada saham HMSP, ICBP, $\mathrm{KLBF}$, dan WOOD memiliki nilai beta lebih besar dari satu sedangkan pada CAPM-Historis dimiliki oleh saham HMSP dan WOOD, artinya saham tersebut berisiko lebih besar dari risiko pasar. Begitu juga jika memiliki nilai beta lebih kecil dari satu, maka saham tersebut berisiko lebih kecil dari risiko pasar.

\subsubsection{Nilai Return Yang Diharapkan Berdasarkan CAPM}

Variabel yang memenuhi pada persamaan CAPM adalah tingkat pengembalian yang diharapkan dari saham ke-i $\left(E\left(r_{i}\right)\right)$, tingkat pengembalian bebas risiko $\left(r_{f}\right)$ menggunakan suku bunga Bank Indonesia sebesar 3,5\%; tingkat pengembalian indeks pasar $\left(E\left(r_{M}\right)\right)$, dan risiko dari saham ke-i $\left(\beta_{i}\right)$. Hasil perhitungan CAPM dapat disajikan pada Tabel 4 dan Tabel 5.

Tabel 4. Hasil Perhitungan Nilai Return Yang

\begin{tabular}{|c|c|c|c|c|}
\hline Saham & $r_{f}$ & $E\left(r_{M}\right)$ & $\begin{array}{l}\text { Beta } \\
\left(\beta_{i}\right)\end{array}$ & $\begin{array}{l}E\left(r_{i}\right) \\
=r_{f} \\
+\left(E\left(r_{M}\right)\right. \\
\left.-r_{f}\right) \beta_{i}\end{array}$ \\
\hline HMSP & 0,035 & $-0,00047$ & 1,18075 & $-0,00688$ \\
\hline ICBP & 0,035 & $-0,00047$ & 0,20786 & 0,02763 \\
\hline KLBF & 0,035 & $-0,00047$ & 0,67198 & 0,01116 \\
\hline UNVR & 0,035 & $-0,00047$ & 0,27375 & 0,02529 \\
\hline WOOD & 0,035 & $-0,00047$ & 1,67418 & $-0,02439$ \\
\hline
\end{tabular}
Diharapkan Pada Masing-masing Saham Menggunakan Beta CAPM-Stokastik

\begin{tabular}{|c|c|c|c|l|}
\hline Saham & $r_{f}$ & $E\left(r_{M}\right)$ & $\begin{array}{l}\text { Beta } \\
\left(\beta_{i}\right)\end{array}$ & $\begin{array}{l}E\left(r_{i}\right) \\
=r_{f} \\
+\left(E\left(r_{M}\right)\right. \\
\left.-r_{f}\right) \beta_{i}\end{array}$ \\
\hline HMSP & 0,035 & $-0,00022$ & 1,90030 & $-0,03194$ \\
\hline ICBP & 0,035 & $-0,00022$ & 1,29882 & $-0,01075$ \\
\hline KLBF & 0,035 & $-0,00022$ & 1,44293 & $-0,01583$ \\
\hline UNVR & 0,035 & $-0,00022$ & 0,38044 & 0,02160 \\
\hline WOOD & 0,035 & $-0,00022$ & 1,05731 & $-0,00224$ \\
\hline
\end{tabular}

Tabel 5. Hasil Perhitungan Nilai Return Yang Diharapkan Pada Masing-masing Saham Menggunakan Beta CAPM-Historis

Berdasarkan Tabel 4 dapat disimpulkan bahwa hasil perhitungan dengan CAPMStokastik pada saham UNVR nilai return yang diharapkan memiliki nilai terbesar yaitu 0,02160 dengan nilai risiko beta sebesar 0,38044 . Sedangkan nilai return yang diharapkan paling kecil sebesar -0,03194 dengan nilai risiko beta sebesar 1,90030 dimiliki oleh saham HMSP. Pada Tabel 5 hasil perhitungan dengan CAPM-Historis pada saham ICBP memiliki nilai return yang diharapkan paling besar yaitu 0,02763 dengan nilai risiko beta sebesar 0,20786. Sedangkan nilai return yang diharapkan paling kecil yaitu $-0,02439$ dengan nilai risiko beta 1,67418 dimiliki oleh saham WOOD.

\subsection{Penentuan Saham Efisien Berdasarkan CAPM}

Penentuan saham efisien dan tidak efisien berdasarkan perhitungan CAPM-Stokastik dan CAPM-Historis dapat disajikan pada Tabel 6.

Pada Tabel 6 hasil evaluasi dengan menggunakan CAPM-Stokastik diperoleh bahwa pada saham HMSP, ICBP, KLBF, dan WOOD termasuk ke dalam saham yang efisien sedangkan pada CAPM-Historis diperoleh 
bahwa saham WOOD adalah saham yang efisien.

Tabel 6. Saham Efisien dan Tidak Efisien Berdas arkan CAPM

\begin{tabular}{|c|c|c|c|c|}
\hline \multirow{2}{*}{ No. } & \multirow{2}{*}{ Saham } & \multicolumn{3}{|c|}{ CAPM-Stokastik } \\
\cline { 3 - 5 } & & $r_{i}$ & $E\left(r_{i}\right)$ & Evaluasi \\
\hline 1. & HMSP & $-0,00297$ & $-0,03194$ & Efisien \\
\hline 2. & ICBP & $-0,00007$ & $-0,01075$ & Efisien \\
\hline 3. & KLBF & $-0,00057$ & $-0,01583$ & Efisien \\
\hline 4. & \multirow{2}{*}{ UNVR } & $-0,00091$ & 0,02160 & $\begin{array}{c}\text { Tidak } \\
\text { Efisien }\end{array}$ \\
\hline 5. & WOOD & 0,00203 & $-0,00224$ & Efisien \\
\hline No. & Saham & \multicolumn{3}{|c|}{ CAPM-Historis } \\
\cline { 3 - 5 } & & $r_{i}$ & $E\left(r_{i}\right)$ & Evaluasi \\
\hline 1. & HMSP & $-0,03181$ & $-0,00688$ & $\begin{array}{c}\text { Tidak } \\
\text { Efisien }\end{array}$ \\
\hline 2. & ICBP & 0,00203 & 0,02763 & $\begin{array}{c}\text { Tidak } \\
\text { Efisien }\end{array}$ \\
\hline 3. & KLBF & $-0,00369$ & 0,01116 & $\begin{array}{c}\text { Tidak } \\
\text { Efisien }\end{array}$ \\
\hline 4. & UNVR & $-0,01165$ & 0,02529 & $\begin{array}{c}\text { Tidak } \\
\text { Efisien }\end{array}$ \\
\hline 5. & WOOD & 0,02308 & $-0,02439$ & Efisien \\
\hline
\end{tabular}

Dikatakan saham yang efisien karena nilai ratarata return saham individu $\left(r_{i}\right)$ lebih besar daripada nilai return yang diharapkan $\left(E\left(r_{i}\right)\right)$. Hasil evaluasi CAPM-Stokastik pada saham UNVR termasuk saham yang tidak efisien sedangkan CAPM-Historis pada saham HMSP, ICBP, KLBF, dan UNVR termasuk saham yang tidak efisien. Disebut saham yang tidak efisien karena nilai rata-rata return saham individu $\left(r_{i}\right)$ lebih kecil daripada nilai return yang diharapkan $\left(E\left(r_{i}\right)\right)$. Sehingga perhitungan dengan menggunakan CAPM-Stokastik menghasilkan empat saham yang efisien dan satu saham yang tidak efisien sedangkan CAPM-Historis menghasilkan satu saham yang efisien yaitu saham WOOD, selain itu saham yang lain merupakan saham yang tidak efisien.

\section{KESIMPULAN DAN SARAN}

CAPM merupakan metode untuk menentukan saham efisien dan tidak efisien berdasarkan selisih antara nilai return individu dengan nilai return yang diharapkan berdasarkan CAPM. Dalam menentukan nilai return saham menggunakan CAPM dengan parameter stokastik langkah pertama adalah menentukan harga estimasi pada masingmasing saham menggunakan model GBG. Model ini dipengaruhi oleh beberapa parameter yaitu harga saham awal, nilai rata-rata return saham $(\mu)$, dan nilai risiko saham $(\sigma)$. Setelah memperoleh harga estimasi saham kemudian menghitung nilai return $\left(r_{i}\right)$ baru dari harga estimasi saham tersebut, kemudian menghitung nilai return pasar $\left(r_{M}\right)$, selanjutnya menghitung nilai beta masing-masing saham $\left(\beta_{i}\right)$, dan menghitung nilai return yang diharapkan $\left(E\left(r_{i}\right)\right.$ berdasarkan CAPM. Perhitungan CAPM-Stokastik diperoleh hasil evaluasi bahwa saham HMSP, ICBP, KLBF, dan WOOD termasuk ke dalam saham yang efisien sedangkan saham UNVR termasuk saham yang tidak efisien. Pada hasil evaluasi menggunakan CAPM-Historis menghasilkan bahwa pada saham HMSP, ICBP, KLBF, dan UNVR adalah saham yang tidak efisien sedangkan saham WOOD merupakan saham efisien.

Saran yang dapat diberikan peneliti untuk penelitian selanjutnya adalah memperluas objek penelitian mengenai perusahaanperusahaan pada sektor lain sehingga dapat mengambil sampel lebih banyak dan periode penelitian yang berbeda sehingga memperoleh hasil yang lebih baik serta menerapkan model GBG dengan lompatan menggunakan beberapa parameter seperti parameter $m u(\mu)$, sigma $(\sigma)$, dan gamma $(\gamma)$ dalam mengestimasi harga saham

\section{DAFTAR PUSTAKA}

Abidin, S.N.Z. dan Jaffar, M.M. 2014. Forecasting Share Prices of Small Size Companies in Bursa Malaysia Using Geometric Brownian Motion. Applied Mathematics and Information Sciences. Vol. 8 No. 1, pp. 107-112. DOI: 10.12785/amis/080112

Ameliah, V., Dharmaw an, K., dan Widana, I.N. 2017. Membandingkan Risiko Sistematis Menggunakan CAPM-GARCH dan CAPMEGARCH. E-Jurnal Matematika. Vol. 6 No. 4, pp. 241-247. DOI: 10.24843/MTK.2017.v06.i04. p172

Dmouj, A. 2006. Stock Price Modelling: Theory and Practice. Amsterdam: BMI Paper. DOI: 10.2139/ssrn.1109160

Haidiati, D., Topowijono., dan Azizah, D.F. 2016. Penerapan Metode Capital Asset Pricing Model (CAPM) Sebagai Dasar Pengambilan Keputusan Investasi Saham (Studi pada Perusahaan yang Terdaftar di 
Indeks IDX30 Periode Juli 2012-Juni 2015). Jurnal Administrasi Bisnis. Vol. 37 No. 2.

Husnan, S. 2015. Dasar-Dasar Teori Portofolio dan Analisis Sekuritas. Yogyakarta: UPP STIM YKPN.

Liadi, E., Dharmawan, K., dan Nilakusmaw ati, D.P.E. 2020. Menentukan Saham Yang Efisien dengan Menggunakan Metode Capital Asset Pricing Model (CAPM). EJurnal Matematika. Vol. 9 No. 1, pp.23-30. DOI:10.24843/MTK.2020.v09.i01.p274

Tandelilin, E. 2017. Pasar Modal: Manajemen Portofolio \& Investasi. Yogyakarta: Kanisius.

Yunita, R., Dharmaw an, K., dan Harini, L.P.I. 2015. Menentukan Portofolio Optimal Pada Pasar Saham Yang Bergerak Dengan Model Gerak Brown Geometri Multidimensi. EJurnal Matematika. Vol. 4 No. 3, pp. 127134.

DOI:

10.24843/MTK.2015.v04.i03.p100 